
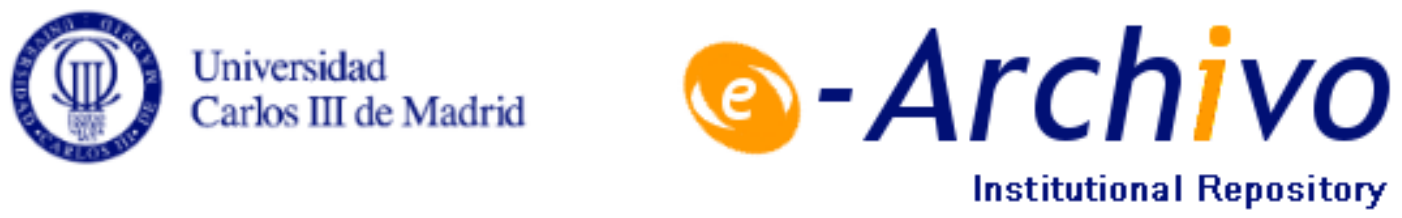

This is a postprint version of the following published document:

Gomes, P., Libero-Cano, A. (2016). Evaluating three decades of the European Capital of Culture programme: a difference-in-differences approach. Journal of Cultural Economics, pp. 1-17. Available in: https://doi.org/10.1007/s10824-016-9281-x

(C) Springer Verlag 


\title{
Evaluating three decades of the European Capital of Culture programme: a difference-in-differences approach
}

\author{
Pedro Gomes ${ }^{1}$ (D) Alejandro Librero-Cano ${ }^{2}$
}

\begin{abstract}
We measure the regional impact of the European Capital of Culture programme using a difference-in-differences approach. We compare the regions of cities that hosted the event with the regions of cities that tried to host it but did not succeed. GDP per capita in hosting regions is $4.5 \%$ higher compared to nonhosting regions during the event, and the effect persists more than 5 years after it. This result suggests that the economic dimension of the event is important and supports claims that the event serves as catalyst for urban regeneration and development.
\end{abstract}

Keywords European Capital of Culture · Difference-in-differences · Culture-led regeneration

JEL Classification R10 $\cdot$ R58 $\cdot$ Z10

We would like to give particular thanks to Nuria Lombana, Sylvain Pasqua, Jeanne Alart, Rodolfo Maslias, Samuel Bentolila, Patricia Melo, Jan Stuhler, Iliana Reggio, seminar participants at the Universidad Carlos III and an anonymous referee.

$\triangle$ Pedro Gomes

pgomes@eco.uc3m.es

Alejandro Librero Cano

k1593899@kcl.ac.uk

1 Department of Economics, Universidad Carlos III de Madrid, c/Madrid 126, 28903 Getafe, Spain

2 Department of Culture Media and Creative Industries, King's College London, London, UK 


\section{Introduction}

The European Capital of Culture, a programme created in 1985, has become a widely coveted cultural event. During a whole year, a designated European city celebrates arts and culture as well as cooperation among the diverse countries that form Europe. Thirty years after its inception, the event, which began as an event to showcase cultural prowess and common bonds among European countries, has evolved. Today, hosting the European Capital of Culture is seen as an opportunity for urban regeneration and a catalyst for social, cultural and economic development.

This study examines the effects of hosting the programme before, during and after the event. The European Capital of Culture's effects are hard to identify, because the hosting city is likely to differ from an average or a random city. To overcome this, we use a difference-in-differences approach: we compare regions of cities that held the event and the regions of runner-up cities. The latter are the cities that manifested a clear willingness to receive the title of European Capital of Culture in a particular year. These cities entered some kind of competition with the winning city at a national or international level, of a lobbying or formal nature but did not see their aspirations fulfilled. The identification assumption is that the "losing" cities form a valid counterfactual for the "winning cities".

The difference-in-differences approach has been used: to assess the impact of other events such as the Olympic Games (Rose and Spiegel 2011; Mehrotra 2012); to quantify the impact of new large manufacturing plants on total factor productivity of incumbent plants in a region (Greenstone et al. 2010); or to measure the impact of new organisations, such as Napster (Hong 2011). However, to the best of our knowledge, this is the first paper that applies this strategy to assess the European Capital of Culture's impact. This approach allows us to deal with the major research gaps highlighted in García and Cox (2013) by providing comparable results among different cities and years and assessing the programme's long-term effects.

After finding which cities hosted and attempted to host the European Capital of Culture, we set up a panel dataset. Due to the lack of comparable data at the city level, we analysed cities through regional data. We opted for the NUTS3 region to which the city belongs to as a unit of analysis. From here on, mentions to winning or runner-up cities refer to the region corresponding to that city. We ended up with a panel of 145 regions with the annual data starting as early as 1984 and ending in 2012. We consider as the main indicator the GDP per capita of the region.

We find that hosting a Capital of Culture raises GDP per capita of the region by $4.5 \%$. This boost starts 2 years before the event and is still present more than 5 years after it. These results are in contrast to the literature on the economic impact of mega-events, such as the Olympic Games, that typically find little or negative effects. For instance, Mehrotra (2012) finds a negative long-run impact on GDP per capita of hosting countries compared to non-hosting countries. Rose and Spiegel (2011) find that the positive effects on exports are equal for both hosting and nonhosting countries.

A recent paper by Steiner et al. (2015) measures the impact of hosting the European Capital of Culture on life satisfaction and on GDP. They find no impact 
on GDP. We improve on their study in three dimensions. First, they compare hosting regions with all other regions, whereas our control group only includes runner-up cities. Second, their unit of analysis is NUTS2. Instead, we use smaller geographic areas NUTS3 where the effects are likely to be concentrated. Third, while they include 28 events, we consider 52. With more events, and more precise geographic area and control group, we do find positive and significant effects of hosting the event.

This paper opens a new avenue for researching European Capitals of Culture, which can help cities to better understand the consequences of their decisions when planning their programme. It may also provide some valuable insight into the EU institutions in charge of regulating the programme and help them refine the European Capital of Culture policy.

\section{European Capital of Culture}

\subsection{History of the programme}

In 1985, the Council of Culture Ministers instituted the European City of Culture programme. The event was created to highlight the richness and diversity of European culture while emphasise its common elements in order to "bring the peoples of the Member States closer together" (Council of European Union 1985). It was also intended to raise European awareness of the chosen city's cultural offer. Initially, and until 1996, the programme depended on the Council of Ministers and the designation of each winner city was made by means of intergovernmental agreements. While the first cities had little time to plan the event, from Glasgow 1990 onwards, the cities would go on to enjoy a 35 years planning span.

A new resolution (Council of European Union 1990) was taken in 1990 to open the programme not only to Member States but to other European countries as well. The designation process was modified: instead of a rotating cycle, the selection should take the form of competition among aspiring cities. Every 2 years, the Council would choose two winning cities from a pool of applicants. The hosting cities would then have a 5- or 6-year planning period.

In 1999, the European Parliament and the Council of the EU agreed to change the programme's name and instituted the "European Capital of Culture" (European Parliament and Council 1999). While the objectives remained largely unchanged, the designation process was again redesigned.

With these new regulations, from 2005, a list was elaborated in which one or two countries were assigned a particular year in rotating turns. Each year, the designated Member States were to hold the event and, at least 4 years prior to the event itself, the national authorities of those countries would nominate one or several cities within their borders. A selection panel of seven independent cultural experts would evaluate the proposals and make a recommendation to the Council that would officially designate the countries' European Capitals of Culture for that year. From 2008, with the actual selection process, there are two European cities in two 
different countries each year, which share the title of European Capital of Culture (with the exception of 2010, when there were three).

A new decision, still in force today, was taken in 2006 (European Parliament and Council 2006) and introduced three major updates: a monitoring panel that kept track of the progress of the designated cities and offered guidance to comply with the objectives and operational goals of the programme; the awarding of the Melina Mercouri Prize upon successful evaluation of the monitoring panel; and the obligation of the Commission to perform an ex-post evaluation assessing the success of the project measured against its set goals and the programme's objectives.

\subsection{Funding and organisation of the event}

Through the history of the programme, cities have resorted to different sources of financing, depending on their geographic situation, their size and other sociopolitical circumstances, drawing financing from national governments (average of $37 \%$ of the total budget), local and regional governments (average of $34 \%$ ), and private sector sponsors (the rest). The European Commission support represents a small proportion of the total budget. It is worth noting, however, that the budgets greatly differ in size and composition across cities, ${ }^{1}$ and that even though a few trends can be noticed analysing the available data, comparison is difficult due to the varied nature of the cities and their celebrations (see García and Cox 2013).

A variety of structures gather and manage this funding and are in charge of the organisation of the event. Although at first direct administration of the event by local authorities was the norm, the most common alternative since 1995 is to institute an independent body that takes the form of a foundation or a not-for-profit organisation, in order to prevent political influence. Despite these measures, local or even regional and national political influence is usually exerted during the organisation stages of the European Capital of Culture (Palmer 2004; García and Cox 2013).

These bodies are responsible for delivering the event and materialising the European Capital of Culture programme. Habitually, preparations take 34 years and include the determination of the events and activities that will take place during the year; communication and publicity of the event and the programme; and infrastructure remodelling and developing in order to enable the city to host the event and attract visitors. Once more, it is difficult to spot valid trends since, due to the approach differences, these preparations, and the financial efforts made to undertake them, vary in size, intensity and form (Palmer 2004).

\subsection{Evaluation of the programme}

After almost three decades of the birth of the European Capital of Culture initiative, it is clear that research is a key tool for many of the event's stakeholders (García and Cox 2013; European Capitals of Culture Policy Group 2010).

\footnotetext{
${ }^{1}$ Acording to Steiner et al. (2015), the budgets ranged from 5.5 million euros in Reykjavik to 59 million euros in Lille.
} 
Some of the most ambitious research makes use of a methodology that combines the reviewing of the existing literature with primary data obtained from questionnaires and interviews. A lot of the literature builds upon two major reports by Myerscough (1994) and Palmer (2004), which cover, respectively, European Capitals of Culture from 1985 to 1995 and from 1995 to 2005.

Many other works in this field use a combination of qualitative and quantitative techniques in order to explain the complex relationships present when a European Capital of Culture is organised: focus groups, face-to-face interviews or questionnaires, as well as press review analysis. Examples that focus more on "soft data" include: the administration of surveys to measure the short-term image effects of the event in Porto and Rotterdam 2001 (Richards et al. 2002); the examination of inhabitant's perceptions of the event in Krakow 2000 and Bruges 2002 (Hughes et al. 2003; Boyko 2007) and the inquiry into press and image effects of the event in Glasgow 1990 (García 2005) and Liverpool 2008 (García 2006, 2010).

Another line of inquiry focuses on "hard data" and purely economic impacts, a methodology almost exclusively used to identify short-term effects. An example is the study by Herrero et al. (2006), of Salamanca 2002 where economic impact is estimated as a combination of the private spending generated by cultural tourism and the measured levels of cultural consumption and investment directly related to the event.

Despite the growing amount of the literature and rising interest on the topic, there are a number of shortcomings and research gaps in European Capitals of Culture studies. The first of them has to do with the impact areas researched. Economic analysis is still predominant, while sociocultural, political or environmental effects are featured much less predominantly in the literature (Langen and Garcia 2009).

Comparability of results is another issue: a great number of reports including those of Myerscough (1994), Palmer (2004) or García and Cox (2013) have highlighted the difficulties in comparing one hosting city to another. First, this is due to the heterogeneity of the organising cities in terms of size, budget, programming approaches, cultural strategies, patrimony endowment and existing amenities. Second, this is due to the heterogeneity of data and researching techniques. Since the beginning of the initiative, there has been a lack of guidelines on data collection and evaluation methods and cities have had different levels of commitment towards gathering and analysing data. No one has attempted to evaluate the programme as a whole in a systematic way so far.

One last research gap, widely noted in the literature, is the absence of wellfounded evidence of long-term effects once the event has been hosted (Langen and Garcia 2009; Palmer 2004; European Capitals of Culture Policy Group 2010). Most of the literature is unable to provide a solid evidence base for long-term effects or is directly focused only in short-term benefits. The regulation introduced in 1999 and onwards by the EU states that the event should be programmed in such a farsighted way that it spawns long-term legacies in order to promote urban development or regeneration and cities claim the title on the basis of this long-term effects. In this context, this research gap becomes more apparent than ever.

We address most of the shortcomings of the literature. First, we evaluate the average effect of the programme since its inception. Second, besides considering GDP per capita, we try to inspect the mechanisms that nurture the potential effects 
by also focussing on value added and employment of particular sectors, namely Construction; Accommodation and food services and Arts, entertainment and recreation. Third, we evaluate the impacts more than 5 years after the event took place.

\section{Methodology}

In order to assess whether the European Capital of Culture programme has an economic impact, we use a difference-in-differences approach. Cities that hosted the European Capital of Culture comprise our treatment group, while the control group encompasses any candidate city that was not selected. The treatment starts, not at the year of the event, but at the year of the announcement. The European Capital of Culture is usually announced several years before the event, but this has changed throughout the history of the programme. In early stages, the host was decided 13 years in advance, whereas in more recent years it is announced 46 years before the event. We distinguish several phases:

Pre-treatment:

- Before the announcement.

Post-treatment:

- Phase I: announcement (from the year of announcement to 3 years before the event).

- Phase II: pre-event (1 2 years before event).

- Phase III: event (year of event).

- Phase IV: short-run (1 2 years after event).

- Phase V: medium-run (3 5 years after event).

- Phase VI: long-run (more than 5 years after event).

The objective of this paper is to analyse the impact of the programme on a series of indicators. Following Mora and Reggio (2013), we consider a flexible specification for the dynamics of the effect, by including the dummies for the several phases of the post-treatment. For each indicator, we run the following regression:

$$
\operatorname{Ind}_{i, t}=\alpha_{i}+\eta_{t}+\sum_{k=I}^{V I} \lambda^{k} D_{i, t}^{k}+\sum_{k=I}^{V I} \gamma^{k}\left(D_{i, t}^{k} \times \operatorname{Host}_{i, t}\right)+\beta \operatorname{Ind}_{i, t}^{c}+\mu_{i, t}
$$

where $\operatorname{Ind}_{i, t}$ is the indicator for region $i$ at time $t$. The regression includes city fixed effects $\alpha_{i}$, year dummies $\eta_{t}$ and an error term $\mu_{i, t}$. A $D_{i, t}^{k}$ dummy is included for every city that takes the value 1 in phase $k$ relative to the event (I VI). Finally, an interaction Host $_{i, t} \times D_{i, t}^{k}$ dummy is also included for winning cities that takes the value 1 in phase $k$. The coefficients $\gamma^{k}$ measure the impact of hosting the event in the different phases. We include $\operatorname{Ind}_{i, t}^{c}$ as the indicator for the country at time $t$, to 
control for general national economic activity. As an alternative specification, we consider the following regression:

$$
\operatorname{Ind}_{i, t}-\operatorname{Ind}_{i, t}^{c}=\alpha_{i}+\eta_{t}+\sum_{k=I}^{V I} \lambda^{k} D_{i, t}^{k}+\sum_{k=I}^{V I} \gamma^{k}\left(D_{i, t}^{k} \times \operatorname{Host}_{i, t}\right)+\mu_{i, t}
$$

where we directly subtract the national indicator and use it as the dependent variable. This specification is similar to specification (1) when $\beta=1$. Although the regions are small enough not to influence the national indicators, the second specification guarantees that there is no endogeneity of the regressors.

Our approach implies three assumptions. The first is the parallel trends assumption, by which the trends of the indicators both in the winning cities and their runners-up are assumed to be parallel in the years prior to the announcement. We explicitly test this assumption in Sect. 5. The second one is that the unobserved heterogeneity of the model is fixed and constant over time. Therefore, unobserved heterogeneity is cancelled out through the differencing process and the estimates are free from omitted variable bias of time-invariant variables, such as natural patrimony or amenities. Another assumption of the difference-in-differences approach is the Stable Unit Treatment Value: an observation in one city should be unaffected by the assignment of the event to another city. In practice, this might not hold. On the one hand, a winner city might take national resources away from a losing city. On the other hand, a winner city might attract foreign tourists to the event that then visit a losing city. These spillovers are hard to measure because they cannot be distinguished from other potential economic driving forces affecting the losing regions. Implicit in our analysis is the assumption that either these spillovers are negligible or the positive spillovers outweigh the negative effects, so the estimated coefficients are a lower bound for the true effect. We think this is a reasonable assumption. In the whole European Capital of Culture literature cited above, we could not find any evidence suggesting that the spillovers to losing cities are sizable.

\section{Data}

Information about cities awarded the European Capital of Culture title is available on the European Commission website, as well as the name of competing cities from recent editions of the programme. However, we had to research in the European Capital of Culture archive in the Directorate General of Education and Culture for earlier bids and references to national and international competition among cities. To further complete this research process, we contacted the organising committees of those events for which there were lacking data. The result of this research process is shown in Table 3 in the Appendix. It is important to notice that the control group is biased towards the more recent events. In the first years, there are many events for which there was no other competing city. We check the robustness of our results by considering only the events from 2000 onwards. 
We then collected data from the Oxford Economics European Cities and Regions database. This database provides statistics for European countries in accordance to the Nomenclature of Territorial Units for Statistics in its smallest regional division (NUTS3). For this, we had to match each city to its respective NUTS3. The convenience of this regional division starting as early as 1980 in some cases and the consistency of the data on the indicators under study have been the major reasons for choosing it. If we were to focus on metropolitan areas, we would not measure the spillovers of hosting the event on nearby cities and villages and it would be harder to find comparable data, which would, arguably, be more prone to measurement error.

Our main analysis focuses on gross domestic product per capita, but we also consider employment and value added of three relevant sub-sectors: (1) construction; (2) accommodation and food services; and (3) arts, entertainment and recreation. We also use data on consumer spending in: Recreational and cultural goods and services and Restaurants and hotels and its sub-components. From the Oxford Economics European Cities and Regions database, we collect yearly data on these variables for every hosting region as well as regions whose cities bid but did not win the title. We also collect data for all the variables for the European countries that have held at least one Capital of Culture since 1985. All the variables are in logarithms to help the interpretation of the coefficients. Once collected, we construct a dataset containing all the indicators for the hosting and runner-up regions.

From the dataset, we exclude those cities for which no data are available: the winning cities of Istanbul and Reykjavik and the runner-up cities of Kiev and Las Palmas de Gran Canaria. We also exclude the observations corresponding to Paphos, Valletta and Luxembourg because the country size renders the regional analysis ineffective. Finally, in the case where a region includes both the winner and a runner-up city in the same year, we consider it as the winner (Cork and Limerick in 2005).

\section{Results}

Figure 1 provides a graphical analysis of the evolution of the average GDP per capita of winners and runners-up, up to 10 years before the event. We highlight the pre-treatment and the post-treatment phases up to the event. Although we do not control for any variable, we can observe a sizable post-treatment positive effect for the winners. The trend for losing cities is slightly negative but not statistically significant.

Table 1 displays the estimated effects on GDP per capita for every phase of the programme. These estimates are calculated under specifications (1) and (2) that include the fixed effects and year dummies. The inspection of Fig. 1 suggests that both winners and runners-up had similar trends prior to the treatment. A statistical test confirms the parallel trends assumption. We run regressions with yearly dummies, from 10 years before the event up to the announcement date. We also include interaction dummies with winner cities. We do not reject that all the interaction coefficients are jointly equal to zero, with p-values above 0.3 . 


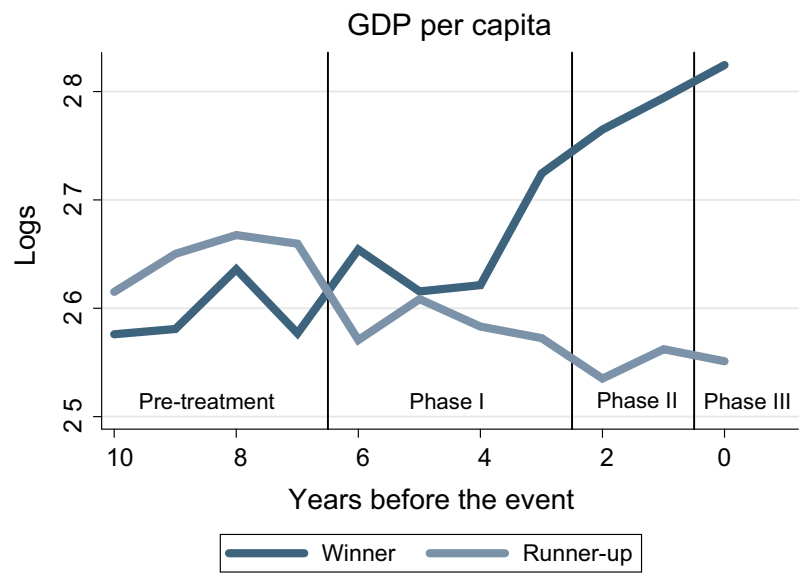

Fig. 1 Average GDP per capita before the event

Table 1 Impact of hosting the European Capital of Culture on GDP per capita

\begin{tabular}{llllll}
\hline Specification & \multicolumn{2}{l}{ All events } & & \multicolumn{2}{l}{ Events after 2000 } \\
\cline { 2 - 3 } \cline { 5 - 6 } & $(1)$ & $(2)$ & & $(1)$ & $(2)$ \\
\hline Host $\times$ Phase I & 0.009 & 0.010 & & 0.009 & 0.009 \\
Host $\times$ Phase II & $(0.66)$ & $(0.72)$ & & $(0.60)$ & $(0.63)$ \\
& 0.040 & 0.039 & & 0.038 & 0.037 \\
Host $\times$ Phase III & $(2.56)^{* *}$ & $(2.54)^{* *}$ & & $(2.31)^{* *}$ & $(2.27)^{* *}$ \\
& 0.047 & 0.046 & & 0.042 & 0.040 \\
Host $\times$ Phase IV & $(2.59)^{* *}$ & $(2.55)^{* *}$ & & $(2.16)^{* *}$ & $(2.09)^{* *}$ \\
& 0.045 & 0.044 & & 0.046 & 0.044 \\
Host $\times$ Phase V & $(2.44)^{* *}$ & $(2.39)^{* *}$ & & $(2.19)^{* *}$ & $(2.10)^{* *}$ \\
& 0.037 & 0.037 & & 0.046 & 0.044 \\
Host $\times$ Phase VI & $(1.98)^{*}$ & $(1.99)^{* *}$ & & $(2.01)^{* *}$ & $(1.92)^{*}$ \\
Parallel trend test & 0.046 & 0.049 & & 0.076 & 0.078 \\
Within $R$ squared & $(1.89)^{*}$ & $(2.03)^{* *}$ & & $(3.01)^{* *}$ & $(3.07)^{* *}$ \\
Between $R$ squared & 0.336 & 0.334 & 0.366 & 0.355 \\
Observations & 0.93 & 0.05 & 0.92 & 0.04 \\
Cities & 0.81 & 0.05 & 0.38 & 0.03 \\
Hosting cities & 2608 & 2608 & 2295 & 2295 \\
\hline$*$ & 145 & 145 & 118 & 118 \\
& 52 & 52 & 37 & 37
\end{tabular}

$*$ and ** Significance at 5 and $10 \%$. T statistics are in parenthesis. Sample is from 1984 to 2012. GDP per capita is in logs. The software used was STATA. The standard errors are clustered by city. All regressions include year dummies. In specification (1), the national GDP per capita is included as an additional regression. In specification (2), its values are subtracted from the regional GDP per capita prior to the regression. ${ }^{\$}$ We estimate the equations adding year dummies from 10 years before the event to the announcement year. We also interact these dummies with being the winner and test the joint significance using an $F$ test. The $p$ value of the $F$ test reported 
Table 2 Impact of hosting the European Capital of Culture on value added and employment per sector

\begin{tabular}{|c|c|c|c|c|c|c|}
\hline & \multicolumn{2}{|c|}{ Construction } & \multicolumn{2}{|c|}{$\begin{array}{l}\text { Accommodation and } \\
\text { food services }\end{array}$} & \multicolumn{2}{|c|}{$\begin{array}{l}\text { Arts, entertainment } \\
\text { and recreation }\end{array}$} \\
\hline & V.A. & Emp. & V.A. & Emp. & V.A. & Emp. \\
\hline \multirow[t]{2}{*}{ Host $\times$ Phase $I$} & 0.055 & 0.024 & 0.005 & 0.014 & 0.009 & 0.105 \\
\hline & $(1.62)$ & $(1.02)$ & $(0.16)$ & $(0.49)$ & $(0.27)$ & $(0.65)$ \\
\hline \multirow[t]{2}{*}{ Host $\times$ Phase II } & 0.059 & 0.016 & 0.027 & 0.012 & 0.022 & 0.114 \\
\hline & $(1.55)$ & $(0.52)$ & $(0.93)$ & $(0.4)$ & $(0.56)$ & $(0.63)$ \\
\hline \multirow[t]{2}{*}{ Host $\times$ Phase III } & 0.054 & 0.011 & 0.044 & 0.032 & 0.024 & 0.126 \\
\hline & $(1.38)$ & $(0.35)$ & (1.33) & (1.12) & $(0.57)$ & $(0.63)$ \\
\hline \multirow[t]{2}{*}{ Host $\times$ Phase IV } & 0.056 & 0.009 & 0.024 & 0.044 & 0.045 & 0.069 \\
\hline & $(1.24)$ & $(0.23)$ & $(0.68)$ & (1.33) & $(1.05)$ & $(0.33)$ \\
\hline \multirow[t]{2}{*}{ Host $\times$ Phase V } & 0.016 & 0.023 & 0.014 & 0.005 & 0.080 & 0.082 \\
\hline & $(0.31)$ & $(0.49)$ & $(0.38)$ & $(0.12)$ & $(1.77)^{*}$ & $(0.42)$ \\
\hline \multirow[t]{2}{*}{ Host $\times$ Phase VI } & 0.005 & 0.034 & 0.020 & 0.023 & 0.026 & 0.057 \\
\hline & $(0.06)$ & $(0.54)$ & $(0.48)$ & $(0.5)$ & $(0.47)$ & $(0.25)$ \\
\hline Within $R$ squared & 0.68 & 0.69 & 0.72 & 0.68 & 0.77 & 0.21 \\
\hline Between $R$ squared & 0.31 & 0.06 & 0.47 & 0.20 & 0.28 & 0.14 \\
\hline Observations & 2891 & 2901 & 2891 & 2900 & 2891 & 2900 \\
\hline Cities & 145 & 145 & 145 & 145 & 145 & 145 \\
\hline Hosting cities & 52 & 52 & 52 & 52 & 52 & 52 \\
\hline
\end{tabular}

* and ** Significance at 5 and $1 \% . T$ statistics are in parenthesis. Variables are in logs. The standard errors are clustered by city. The regressions are based on specification (1) and include year dummies as controls

GDP per capita increases in hosting regions when measured against losing regions. This increase, significant using both specifications, ranges from 3.7 to $4.9 \%$ and appears in every phase from the pre-event phase onwards. When formally testing that the coefficients from Phase II to Phase VI are equal, we do not reject the hypotheses with p-values above 0.7 in the two specifications.

When excluding the first 15 years of the event, the most interesting difference relates to the long-run coefficient. The coefficients are statistically significant and with a magnitude close to $8 \%$, suggesting that the most recent events had a stronger and more long-lasting economic impact. We also divide the sample by population and level of GDP per capita and find that there are no significant differences in the sub-groups.

We ran two other sets of regressions with restricted samples: (1) only keeping events that had competing cities (17 events) and (2) including only close runners-up $\left(23 \operatorname{cities}^{2}\right)$. As we restrict the sample, we estimate only one coefficient for the post-

\footnotetext{
2 These are one or two cities per event that we could identify as being close runners up. These are in bold in Table 3. In some cases, one or two cities went on to the preselection phase in the later years, when a two phase selection process was stablished. In other cases, there was only one or two cities competing with the winner.
} 
treatment that includes Phase II onwards. In both cases, the estimated coefficients are between 0.036 and 0.04 , and statistically significant.

Table 2 gives the estimated effects that the programme has on the value added and employment of three economic sectors related to the celebration of the event: Construction; Accommodation and food services and Arts, entertainment and recreation. Unfortunately, no conclusions can be drawn on the mechanism through which hosting the event raises GDP per capita, as none of the coefficients is significant. As a robustness test, we also used Expenditure on: (1) Restaurants and hotels and (2) Recreational and cultural goods and services. The results are reported in Table 5 in the Appendix and again point to no statistically significant differences between hosting and non-hosting regions. On one hand, it might suggest that the GDP per capita increase is due to an increase in general economic activity and is not linked to a development of a particular sector. On the other hand, it could be simply due to measurement error, which becomes a more serious problem when using more disaggregated data both by region and by sector.

\section{Conclusion}

The European Capital of Culture programme does have an impact in hosting regions. When compared to runner-up regions, Capitals of Culture see a significant increase in GDP per capita. This increase is sizable in magnitude and may justify the will of the cities to host the event. The impact has a similar size through all of the programme's stages, from the pre-event phase to more than 5 years after the event.

These results are in contrast to the literature on the economic impact of megaevents, such as the Olympic Games, that typically find little or negative effects (Mehrotra 2012, or Rose and Spiegel 2011). While most of these papers focus on the aggregate effects, this paper is concerned only with the regional impact. However, these differences are most likely due to the fact that the European Capital of Culture is a very different type of event. It involves lower costs than mega-events, and usually the programme is created around the already existing cultural patrimony of the city. Also, the benefits of hosting the Capital of Culture last for a year, while for the mega-events, they are usually concentrated in a period up to a month, which puts strain on the capacity constrain.

Ideally, one would want to understand the mechanisms behind this positive economic effect. Upon studying the individual impacts of the relevant economic sectors involved in the organisation of a European Capital of Culture, we are unable to determine the specific source of increased economic activity. Part of the problem might be due to the heterogeneity of the characteristics of the event in different cities. It might also be attributed to measurement error. We have tried to gather more data that could allow us to inspect the mechanism, but comparable data are not available at a regional level or a city level with a long enough time series.

Another open question is whether there is new growth in winning cities that spills over neighbouring regions or whether the growth is mainly due to a redistribution of growth from other cities. The difference-in-differences approach can be used to measure spillover effects from winners to losers by comparing neighbouring regions 
of winning cities with neighbouring regions of losing cities. In future research, we will be able to address this question.

This way of analysing the European Capital of Culture programme has the benefit of studying it as a whole through the entirety of its history. Despite the positive conclusion, much has to be done still if the potential of the European Capital of Culture is to be fully materialised, in particular in terms of its cultural ambitions. Planners and European institutions alike should aim at creating stronger links between the cultural and economic dimension of the event. The spillage effects of this effort will increase the size of the programme's impact, and it will enable cities to develop their cultural tissues along with their economies.

As a tool for better planning, more research needs to be done to provide further evidence for the long-term claims of the hosting cities and regions. The availability of the list of runners-up opens a new avenue for European Capital of Culture researchers that can apply a difference-in-differences strategy to other data.

\section{Appendix}

See Tables 3, 4, 5 and 6.

Table 3 Summary of winner and other candidate cities

\begin{tabular}{llll}
\hline Year of event & Year of announcement & Winner & Other candidate cities \\
\hline 1985 & 1984 & Athens & \\
1986 & 1985 & Florence & \\
1987 & 1985 & Amsterdam & \\
1988 & 1985 & Berlin & Bonn, Munich \\
1989 & 1986 & Paris & \\
1990 & 1986 & Glasgow & Bath, Bristol, Cardiff, \\
& & & Cambridge, Leeds, Liverpool, \\
& & & Swansee, Edinburgh \\
1991 & 1989 & Dublin & Cork \\
1992 & 1988 & Madrid & \\
1993 & 1988 & Antwerp & Liège \\
1994 & 1989 & Lisbon & \\
1995 & 1989 & Luxembourg & \\
1996 & 1989 & Copenhagen & \\
1997 & 1992 & Thessaloniki & Estambul, Budapest \\
1998 & 1993 & Stockholm & Prague \\
1999 & 1993 & Weimar & Nüremberg \\
2000 & 1995 & Avignon & \\
2000 & 1995 & Bergen & \\
2000 & 1995 & Bologna & \\
2000 & 1995 & Brussels & \\
\hline
\end{tabular}


Table 3 continued

\begin{tabular}{|c|c|c|c|}
\hline Year of event & Year of announcement & Winner & Other candidate cities \\
\hline 2000 & 1995 & Helsinki & \\
\hline 2000 & 1995 & Krakow & \\
\hline 2000 & 1995 & Reykjavik & \\
\hline 2000 & 1995 & Prague & \\
\hline 2000 & 1995 & Santiago de Compostela & \\
\hline 2001 & 1998 & Porto & \\
\hline 2001 & 1998 & Rotterdam & \\
\hline 2002 & 1998 & Bruges & Mons \\
\hline 2002 & 1998 & Salamanca & Granada, Barcelona, Valencia \\
\hline 2003 & 1998 & Graz & \\
\hline 2004 & 1998 & Genoa & \\
\hline 2004 & 1998 & Lille & \\
\hline 2005 & 2001 & Cork & Galway, Limerick, Waterford \\
\hline 2006 & 2002 & Patras & \\
\hline 2007 & 2004 & Luxembourg & \\
\hline 2007 & 2004 & Sibiu & \\
\hline 2008 & 2004 & Liverpool & $\begin{array}{l}\text { Birmingham, Bristol, Cardiff, } \\
\text { Newcastle, Oxford, Belfast, } \\
\text { Bradford, Brighton, } \\
\text { Canterbury, Inverness and the } \\
\text { Highlands, Norwich }\end{array}$ \\
\hline 2008 & 2004 & Stavanger & \\
\hline 2009 & 2005 & Linz & \\
\hline 2009 & 2005 & Vilnius & \\
\hline 2010 & 2006 & Essen & Görlitz-Zgorzelec, Bremen \\
\hline 2010 & 2006 & Istanbul & Kiev \\
\hline 2010 & 2006 & Pécs & $\begin{array}{l}\text { Budapest, Debrecen, Miskolc, } \\
\text { Gyór, Kaposvár, Kecskemét, } \\
\text { Sopron, Székesfehérvár, } \\
\text { Veszprém }\end{array}$ \\
\hline 2011 & 2007 & Turku & $\begin{array}{l}\text { Jyväskylä, Lahti, Mänttä, Oulu, } \\
\text { Rovaniemi, Tampere }\end{array}$ \\
\hline 2011 & 2007 & Tallinn & Tartu, Haapsalu, Pärnu, Rakvere \\
\hline 2012 & 2008 & Maribor & Celje, Koper, Ljubljana \\
\hline 2012 & 2008 & Guimarães & \\
\hline 2013 & 2008 & Marseille & $\begin{array}{l}\text { Amiens, Lyon, Saint Etienne, } \\
\text { Strasbourg, Bordeaux, Nice, } \\
\text { Toulouse }\end{array}$ \\
\hline 2013 & 2008 & Košice & $\begin{array}{l}\text { Bratislava, Nitra, Trencin, } \\
\text { Banska Bystrica, Martin, } \\
\text { Trnava, Dolny Kubin, Presov }\end{array}$ \\
\hline 2014 & 2009 & Riga & Cesis, Liepaja, Jurmala \\
\hline 2014 & 2009 & Umea & Lund, Gavle, Uppsala \\
\hline 2015 & 2010 & Mons & \\
\hline
\end{tabular}


Table 3 continued

\begin{tabular}{|c|c|c|c|}
\hline Year of event & Year of announcement & Winner & Other candidate cities \\
\hline 2015 & 2010 & Plzeň & Ostrava, Hradec Králové, \\
\hline 2016 & 2011 & San Sebastián & $\begin{array}{l}\text { Córdoba, Alcalá de Henares, } \\
\text { Burgos, Cáceres, Cuenca, } \\
\text { Málaga, Murcia, Oviedo, Las } \\
\text { Palmas de Gran Canaria, } \\
\text { Pamplona, Santander, Segovia, } \\
\text { Tarragona y Zaragoza }\end{array}$ \\
\hline 2016 & 2011 & Wrocław & $\begin{array}{l}\text { Białystok, Bydgoszcz, Gdańsk, } \\
\text { Katowice, Lublin, Łódź, } \\
\text { Poznań, Szczecin, Toruń, } \\
\text { Warszawa }\end{array}$ \\
\hline 2017 & 2012 & Aarhus & Sønderborg \\
\hline 2017 & 2012 & Paphos & Nicosia, Limassol \\
\hline 2018 & 2012 & Leeuwarden & Eindhoven, Maastricht \\
\hline 2018 & 2013 & Valletta & \\
\hline
\end{tabular}

In bold are the cities identified as close runners up

Table 4 Data description. Source: Oxford Economics European Cities and Regions database

\begin{tabular}{|c|c|c|}
\hline \multirow[t]{2}{*}{ Indicator } & \multicolumn{2}{|c|}{$\begin{array}{l}\text { Cross sectional mean and standard deviation } \\
\text { at time of event }\end{array}$} \\
\hline & Winners & Runners up \\
\hline Gross domestic product per capita & $3.131(0.619)$ & $2.954(0.631)$ \\
\hline Millions of Euros, 2005 prices, logs & {$[31]$} & [48] \\
\hline \multicolumn{3}{|l|}{ Gross value added } \\
\hline Accommodation and food services & $12.682(1.078)$ & $12.164(1.376)$ \\
\hline Millions of Euros, 2005 prices, logs & {$[33]$} & {$[51]$} \\
\hline Arts, entertainment and recreation & $11.857(1.001)$ & $11.475(1.095)$ \\
\hline Millions of Euros, 2005 prices, logs & [33] & [51] \\
\hline Construction & $13.089(1.140)$ & $13.088(1.170)$ \\
\hline Millions of Euros, 2005 prices, logs & {$[33]$} & [51] \\
\hline \multicolumn{3}{|l|}{ Workplace employment } \\
\hline Accommodation and food services & $9.450(0.764)$ & $9.188(0.984)$ \\
\hline Persons, thousands, logs & {$[32]$} & {$[51]$} \\
\hline Arts, entertainment and recreation & $8.383(0.757)$ & $8.235(0.910)$ \\
\hline Persons, thousands, logs & {$[32]$} & [51] \\
\hline Construction & $9.951(0.707)$ & 9.607 (0.909) \\
\hline Persons, thousands, logs & {$[32]$} & [51] \\
\hline \multicolumn{3}{|l|}{ Expenditure } \\
\hline Recreational and cultural goods and services & $13.462(0.934)$ & $13.156(1.172)$ \\
\hline Millions of Euros, 2005 prices, logs & {$[25]$} & [37] \\
\hline Restaurants and hotels & $13.345(1.004)$ & $12.937(1.293)$ \\
\hline
\end{tabular}


Table 4 continued

\begin{tabular}{lll}
\hline Indicator & \multicolumn{2}{l}{$\begin{array}{l}\text { Cross sectional mean and standard deviation } \\
\text { at time of event }\end{array}$} \\
\cline { 2 - 3 } Millions of Euros, 2005 prices, logs & Winners & Runners up \\
\hline Population & {$[25]$} & {$[37]$} \\
Persons, thousands, logs & $13.353(0.686)$ & $13.006(0.765)$ \\
Workforce & {$[31]$} & {$[48]$} \\
Persons, thousands, logs & $12.616(0.565)$ & $12.152(0.765)$ \\
ILO unemployment rate & {$[28]$} & {$[48]$} \\
Percentage & $8.615(4.646)$ & $8.929(4.103)$ \\
\hline
\end{tabular}

Cross sectional mean reported, standard errors in brackets, number of city observations in square brackets

Table 5 Impact of hosting the European Capital of Culture on other variables

\begin{tabular}{|c|c|c|c|c|c|}
\hline & \multicolumn{2}{|l|}{ Expenditure } & \multicolumn{3}{|l|}{ Others } \\
\hline & $\begin{array}{l}\text { Restaurants } \\
\text { and hotels }\end{array}$ & $\begin{array}{l}\text { Recreational and } \\
\text { cultural goods } \\
\text { and services }\end{array}$ & Population & Workforce & $\begin{array}{l}\text { Unemployment } \\
\text { rate }\end{array}$ \\
\hline \multirow[t]{2}{*}{ Host $\times$ Phase I } & 0.009 & 0.015 & 0.012 & 0.007 & 1.233 \\
\hline & $(0.74)$ & $(1.43)$ & $(1.41)$ & $(0.49)$ & $(2.17)^{* *}$ \\
\hline \multirow[t]{2}{*}{ Host $\times$ Phase II } & 0.002 & 0.005 & 0.011 & 0.004 & 0.732 \\
\hline & $(0.12)$ & $(0.38)$ & $(1.23)$ & $(0.32)$ & $(1.43)$ \\
\hline \multirow[t]{2}{*}{ Host $\times$ Phase III } & 0.016 & 0.007 & 0.011 & 0.010 & 0.657 \\
\hline & $(1.06)$ & $(0.44)$ & $(0.93)$ & $(0.64)$ & $(1.09)$ \\
\hline \multirow[t]{2}{*}{ Host $\times$ Phase IV } & 0.007 & 0.001 & 0.015 & 0.013 & 0.279 \\
\hline & $(0.4)$ & $(0.03)$ & $(1.12)$ & $(0.75)$ & $(0.42)$ \\
\hline \multirow[t]{2}{*}{ Host $\times$ Phase $V$} & 0.011 & 0.004 & 0.027 & 0.045 & 0.929 \\
\hline & $(0.57)$ & $(0.24)$ & $(1.53)$ & $(1.75)^{*}$ & $(1.16)$ \\
\hline \multirow[t]{2}{*}{ Host $\times$ Phase VI } & 0.027 & 0.022 & 0.023 & 0.046 & 2.163 \\
\hline & $(1.29)$ & $(1.2)$ & $(0.8)$ & $(1.41)$ & $(1.93)^{*}$ \\
\hline Within $R$ squared & 0.94 & 0.98 & 0.61 & 0.65 & 0.788 \\
\hline Between $R$ squared & 0.45 & 0.29 & 0.06 & 0.05 & 0.443 \\
\hline Observations & 2118 & 2118 & 2899 & 2319 & 2317 \\
\hline Cities & 141 & 141 & 145 & 145 & 145 \\
\hline Hosting cities & 50 & 50 & 52 & 52 & 52 \\
\hline
\end{tabular}

* and ** Significance at 5 and $1 \%$. $T$ statistics are in parenthesis. Variables are in logs expect for unemployment rate. The standard errors are clustered by city. The regressions are based on specification (1) and include year dummies as controls 
Table 6 Impact of hosting the European Capital of Culture on GDP per capita, restricted sample

\begin{tabular}{|c|c|c|c|c|}
\hline \multirow[t]{2}{*}{ Specification } & \multicolumn{2}{|c|}{ Only events with runners up } & \multicolumn{2}{|c|}{ Only close runners up } \\
\hline & (1) & (2) & (1) & (2) \\
\hline \multirow[t]{2}{*}{ Host $\times$ Phase I } & 0.006 & 0.007 & 0.002 & 0.003 \\
\hline & $(0.46)$ & $(0.48)$ & $(0.16)$ & $(0.18)$ \\
\hline \multirow[t]{2}{*}{ Host $\times$ Phase II VI } & 0.036 & 0.036 & 0.040 & 0.039 \\
\hline & $(1.73)^{*}$ & $(1.70)^{*}$ & $(5.27)^{* *}$ & $(5.19)^{* *}$ \\
\hline Within $R$ squared & 0.93 & 0.05 & 0.92 & 0.04 \\
\hline Between $R$ squared & 0.83 & 0.01 & 0.79 & 0.05 \\
\hline Observations & 2027 & 2027 & 1325 & 1325 \\
\hline Cities & 110 & 110 & 75 & 75 \\
\hline Hosting cities & 17 & 17 & 52 & 52 \\
\hline
\end{tabular}

* and ** Significance at 5 and $10 \% . T$ statistics are in parenthesis. Sample is from 1984 to 2012. The close runners up are identified in bold in Table 3. GDP per capita is in logs. The standard errors are clustered by city. All regressions include year dummies. In specification (1), the national GDP per capita is included as an additional regression. In specification (2), its values are subtracted from the regional GDP per capita prior to the regression

\section{References}

Boyko, C. T. (2007). Are you being served? The impacts of a tourist hallmark event on the place meanings of residents. Event Management, 11(4), 161177.

Council of European Union (1985). Resolution of the ministers responsible for cultural affairs, meeting within the council, of 13 June 1985 concerning the annual event 'European City of Culture'. 85/C $153 / 02$.

Council of European Union (1990). Conclusions of the ministers of culture meeting within the council of 18 May 1990 on future eligibility for the 'European City of Culture' and on a special European Cultural Month event. 85/C 153/02.

European Capitals of Culture Policy Group. (2010). An international framework of good practice in research and delivery of the European Capital of Culture programme. Liverpool: University of Liverpool.

European Parliament and Council (1999). Decision 1419/1999/EC of the European Parliament and of the Council of 25 May 1999. European Council. http://eur lex.europa.eu/LexUriServ/LexUriServ. do? uri CONSLEG:1999D1419:20040501:EN:PDF.

European Parliament and Council (2006). Decision No. 1622/2006/EC of the European Parliament and of the Council of 24 October 2006. European Council. http://eur lex.europa.eu/LexUriServ/ LexUriServ.do?uri OJ:L:2006:304:0001:0006:EN:PDF.

Garcia, B. (2005). Deconstructing the city of culture: The long term cultural legacies of Glasgow 1990. Urban Studies, $42(5$ 6), 841868.

Garcia, B. (2006). Media impact assessment (part I). Baseline findings on Liverpool press coverage before the European Capital of Culture (1996 2005). Impacts 08, Liverpool.

Garcia B. (2010). Media impact assessment (part II). Evolving press and broadcast narratives on Liverpool from 1996 to 2009. Impacts 08, Liverpool.

García, B., \& Cox, T. (2013). European capitals of culture: Success strategies and long term effects. Directorate general for internal policies, policy department B: Structural and cohesion policies. http://www.europarl.europa.eu/RegData/etudes/etudes/join/2013/513985/IPOLCULT ET\%282013\% 29513985 EN.pdf.

Greenstone, M., Hornbeck, R., \& Moretti, E. (2010). Identifying agglomeration spillovers: Evidence from winners and losers of large plant openings. Journal of Political Economy, 118(3), 536598. 
Herrero, L. C., Sanz, J. Á., Devesa, M., Bedate, A., \& Del Barrio, M. J. (2006). The economic impact of cultural events a case study of salamanca 2002, European Capital of Culture. European Urban and Regional Studies, 13(1), 4157.

Hong, S. H. (2011). Measuring the effect of napster on recorded music sales: Difference in differences estimates under compositional changes. Journal of Applied Econometrics, 28(2), 297324.

Hughes, H., Allen, D., \& Wasik, D. (2003). The significance of European "Capital of Culture" for tourism and culture: The case of Kraków 2000. International Journal of Arts Management, 5(3), 1223 .

Langen, F., \& Garcia, B. (2009). Measuring the impacts of large scale cultural events: A literature review. Impacts 08: The Liverpool Model, European Capital of Culture Research Programme.

Mehrotra, A. (2012). To host or not to host? A comparison study on the long run impact of the olympic games. Michigan Journal of Business, 5(2), 6192.

Mora, R., \& Reggio, E. (2013) Treatment effect identification using alternative parallel assumptions, Universidad Carlos III de Madrid working paper.

Myerscough, J. (1994). European cities of culture and cultural months: Summary report. Network of Cultural Cities of Europe.

Palmer, R. (2004). European capitals/cities of culture. Study on the European cities and capitals of culture and the European cultural months (1995 2004). Palmer/Rae Associates, European Commission, Brussels.

Richards, G., Hitters, E., \& Fernandes, C. (2002). Rotterdam and Porto: Cultural capitals 2001: Visitor research. Arnhem: Atlas.

Rose, A., \& Spiegel, M. (2011). The olympic effect. Economic Journal, 121(553), 652677.

Steiner, L., Frei, B., \& Hotz, S. (2015). European capitals of culture and life satisfaction. Urban Studies, 52(2), 374394. 